\section{Is there scope for providing oral cancer health advice in dental access centres?}

\author{
M. Williams ${ }^{1}$ and S. Scott ${ }^{2}$
}

VERIFIABLE CPD PAPER
IN BRIEF
- Highlights the importance of the combination of alcohol and tobacco usage as risk factors for oral cancer.
- Encourages all dentists to ask appropriate questions about patients' smoking and drinking habits as part of a minimum data set during their examination process.
- Suggests dental access centres are potential locations for primary prevention of oral cancer.

\begin{abstract}
Objective There are more than 3,500 new cases of oral cancer each year in the UK. The purpose of this study was to establish the proportion of patients attending a dental access centre that are at risk of developing oral cancer because of lifestyle habits, and in turn determine whether access centres are a suitable location for the provision of advice on smoking cessation and alcohol consumption. Methods Data were collected prospectively about the smoking and drinking habits of patients attending a dental access centre in Nottingham. Three hundred and fifty-nine patients attended the dental access centre during the survey period. Patients were categorised into one of four groups ranging from low risk to high risk, according to their smoking history and alcohol intake. Results More than 50\% of patients attending the dental access centre were smokers, with almost $40 \%$ of the patients in high or very high tobacco and alcohol use groups. The majority of attendees were under 45 years of age. Conclusions Significant numbers of patients attending the dental access centre have lifestyle habits that make them vulnerable to oral cancer. Dental access centres could usefully provide opportunistic health messages to patients about risk factors in the development of oral cancer.
\end{abstract}

\section{INTRODUCTION}

Oral squamous cell carcinoma (OSCC) is among the ten most common cancers worldwide. ${ }^{1}$ The incidence in the UK is approximately 3,885 cases per annum, with a mortality rate of just over 50\% despite treatment. ${ }^{2}$ The detection of oral cancer at an early stage is the most effective means to improve survival and reduce morbidity, with five year survival rates increasing to $80 \%$ when lesions are found and treated early. ${ }^{3}$ Given these statistics it is important to develop primary and secondary prevention strategies to reduce the burden of oral cancer.

OSCC is seen predominantly in males, although the male:female differential

\footnotetext{
1*General Dental Practitioner and Specialist in Oral Surgery, Barn Court, Cropwell Road, Langar, Nottinghamshire, NG13 9HD; ${ }^{2}$ Lecturer in Health Psychology, Department of Oral Health Services Research \& Dental Public Health, Dental Institute, King's College London, Caldecot Road, Camberwell, London, SE5 9RT

${ }^{*}$ Correspondence to: Mr Mike Williams

Email: mike.williamsmwdental@hotmail.co.uk
}

${ }^{\circ}$ British Dental Journal 2008 is decreasing. ${ }^{1}$ Age, tobacco and alcohol dominate the oral cancer landscape, and the combination of tobacco and alcohol are particularly important aetiological factors in the development of OSCC. ${ }^{4,5}$ As such, primary prevention initiatives (ie smoking cessation, reduction of alcohol consumption) should be directed at those who are under 45 years old, who use tobacco and are moderate to heavy drinkers. Secondary prevention initiatives (ie promotion of regular self or professional examination, prompt help-seeking for potentially malignant oral symptoms) should be directed at those who are over 45 years of age and who use tobacco and are moderate to heavy drinkers.

Although it would appear that tobacco usage is widely recognised by patients as a risk factor for OSCC, the effect of alcohol is not. ${ }^{6}$ The dental practice provides a potential opportunity to provide oral health promotion services.

Dental access centres were set up as a Government initiative following concerns about the lack of readily available NHS dental treatment for some patient groups within the community. Prior to April 2006, access centres provided
NHS dental treatment only for those patients who were not already registered with an NHS dentist. Following contract changes in April 2006 the access centres have been available to all patients, but obviously attract a different type of client to a family-orientated dental practice.

The purpose of this paper is to determine if significant numbers of patients attending the dental access centre in Nottingham have lifestyle habits (smoking and alcohol consumption) that make them vulnerable to oral cancer, and consider whether such access centres may be a useful vehicle for the provision of opportunistic health messages to high risk patients.

\section{METHOD}

In the period 1-31 May 2006, the records of 359 patients seen consecutively at the 'Integrated Dental Unit' (IDU), a dental access centre in Nottingham, were reviewed. Each patient was seen by one of five dentists employed in the centre, and as part of the consultation each patient completed a medical history questionnaire. This routine data collection followed the IDU's ethical guidelines. 


\begin{tabular}{|c|c|c|}
\hline Variable & $\mathrm{N}$ & $\%$ \\
\hline \multicolumn{3}{|l|}{$\begin{array}{l}\text { Sex } \\
(n=354)\end{array}$} \\
\hline Female & 158 & 45 \\
\hline Male & 196 & 55 \\
\hline $\begin{array}{l}\text { Age } \\
(n=358)\end{array}$ & $\begin{array}{l}\text { Mean }=34 \text { yrs } \\
(S D=15.2)\end{array}$ & - \\
\hline Under 45 yrs & 285 & 80 \\
\hline $45-60$ yrs & 49 & 14 \\
\hline Over 60 yrs & 24 & 7 \\
\hline \multicolumn{3}{|l|}{$\begin{array}{l}\text { Alcohol use } \\
(n=342)\end{array}$} \\
\hline Non-drinker & 144 & 42 \\
\hline$\leq 20$ units / week & 176 & 52 \\
\hline$>20$ units / week & 22 & 6 \\
\hline \multicolumn{3}{|l|}{$\begin{array}{l}\text { Tobacco use } \\
(n=346)\end{array}$} \\
\hline Non-smoker & 166 & 48 \\
\hline$\leq 20$ cigarettes / day & 165 & 48 \\
\hline$>20$ cigarettes / day & 15 & 4 \\
\hline
\end{tabular}

The questionnaire requested information on smoking and drinking habits and asked for an estimate of cigarette and alcohol use (cigarettes per day and units of alcohol per week). Using this information the patients were placed in one of four groups, categorised by tobacco and alcohol use. This was not an attempt to classify the true relative risks, but to give an indication of the target groups that might benefit from brief public health interventions given the limited resources available. The four groups were as follows:

- Low tobacco and alcohol use group: non-smokers who either do not drink alcohol or drink less than 20 units per week

- Moderate tobacco and alcohol use group: smokers who do not drink alcohol and who smoke up to 20 cigarettes per day

- High tobacco and alcohol use group: smokers who consume up to 20 cigarettes per day and drink up to 20 units per week

- Very high tobacco and alcohol use group: smokers using in excess of 20 cigarettes per day and/or drinking in excess of 20 units of alcohol per week.

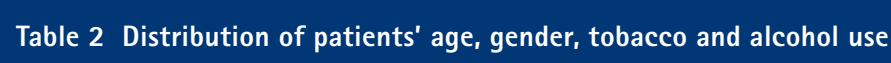

\begin{tabular}{|c|c|c|c|c|c|c|c|c|c|}
\hline & & \multicolumn{8}{|c|}{ Tobacco and alcohol use } \\
\hline & & \multicolumn{2}{|l|}{ Low } & \multicolumn{2}{|c|}{ Moderate } & \multicolumn{2}{|c|}{ High } & \multicolumn{2}{|c|}{ Very high } \\
\hline & & $\mathrm{N}$ & (\%) & $\mathrm{N}$ & $(\%)$ & $\mathrm{N}$ & $(\%)$ & $\mathrm{N}$ & $(\%)$ \\
\hline \multirow[t]{3}{*}{ Under 45 yrs } & Male & 56 & $(17.1)$ & 15 & $(4.6)$ & 47 & (14.3) & 18 & (5.5) \\
\hline & Female & 61 & (18.6) & 22 & (6.7) & 35 & (10.7) & 6 & (1.8) \\
\hline & Total & 117 & $(35.7)$ & 37 & (11.3) & 82 & $(25.0)$ & 24 & (7.3) \\
\hline \multirow[t]{3}{*}{$45-60$ yrs } & Male & 12 & (3.7) & 4 & $(1.2)$ & 6 & (1.8) & 7 & (2.1) \\
\hline & Female & 9 & (2.7) & 3 & $(0.9)$ & 3 & $(0.9)$ & 0 & $(0.0)$ \\
\hline & Total & 21 & $(6.4)$ & 7 & $(2.1)$ & 9 & (2.7) & 7 & (2.1) \\
\hline \multirow[t]{3}{*}{ Over 60 yrs } & Male & 8 & $(2.4)$ & 1 & $(0.3)$ & 2 & $(0.6)$ & 2 & (0.6) \\
\hline & Female & 9 & (2.7) & 2 & $(0.6)$ & 0 & $(0.0)$ & 0 & (0) \\
\hline & Total & 17 & $(5.2)$ & 3 & $(0.9)$ & 2 & $(0.6)$ & 2 & $(0.6)$ \\
\hline \multicolumn{2}{|l|}{ TOTAL* } & 157 & (47.1) & 48 & (14.4) & 95 & (28.5) & 33 & (9.9) \\
\hline
\end{tabular}

\section{RESULTS}

In the study period, a total of 359 patients attended for dental care, 24 of whom did not respond fully to the questions yet were still included in the analysis where data was available. The patient characteristics are displayed in Table 1 and the distribution of patients by their gender and tobacco and alcohol use is shown in Table 2.

Fifty-two percent of patients attending the IDU were smokers and nearly 40\% were in the high or very high tobacco and alcohol use groups. The low tobacco and alcohol use group included 20 patients under the age of 10 years, who if excluded would reduce the low tobacco and alcohol use group to only $41 \%$ of the study sample. Also, 33 patients in this ostensibly non-smoking group had smoked in the past.

The age profile of the study population was shifted to the left, with just $7 \%$ of patients attending the IDU falling into the peak incidence age range for oral cancer (over 60 years), whilst $80 \%$ of patients were under the age of 45 (see Table 1). In the low tobacco and alcohol use group, males and females were equally represented, whereas males predominated in the higher tobacco and alcohol use groups (see Table 2).

\section{DISCUSSION}

Analyses of data provided by patients attending the Integrated Dental Unit (IDU) in Nottingham showed that over $50 \%$ were smokers, compared to a national average of 24\%.7 Almost 40\% of patients smoked up to or more than 20 cigarettes per day and drank up to or more than 20 units of alcohol per week. In addition, the majority of patients in these groups were male, in a disease process where being female is a survival characteristic. ${ }^{1}$ Information provided by patients was taken at face value; there were no secondary questions to check the veracity of the responses, and this may be a source of under-reporting. ${ }^{8,9}$ Furthermore, the results are based on a single dental access centre and as such it is questionable as to whether the findings are generalisable to dental access centres throughout the rest of the United Kingdom. Future research should therefore include multi-centre studies to address this limitation.

Paradoxically, although it appears that a significant proportion of patients attending the access centre have the risk factors for oral cancer, few oral cancers will present clinically at the IDU as patients are predominantly under 45 years old. Thus the value of oral screening and provision of information about 
self examination for these individuals is limited (unless a current trend of increasing prevalence of oral cancer in younger patients continues). Of much greater importance is advice about risk factors, as it is likely that in due course, some of these young patients with adverse lifestyle habits will develop oral cancer in later life.

A 1970s UK government report ${ }^{10}$ emphasised the role of the dental profession in the early recognition of oral cancer via opportunistic oral mucosal screening. This was based on the premise that dentists had an in-depth knowledge and ready access to the oral cavity. However, the reality is that those most at risk of developing oral cancer are the least likely to visit a dentist regularly. ${ }^{11,12}$ Even so, a recent study investigating the costeffectiveness of screening for oral cancer concluded that opportunistic screening of high-risk groups in the general dental practice may be cost effective, particularly if targeted towards 40-60 year olds. ${ }^{13}$ Thus, dental access centres could incorporate opportunistic oral mucosal screening into their practice.

Patient information leaflets have been shown to be effective in increasing knowledge, awareness and perceived risk of oral cancer. ${ }^{14-16}$ Furthermore, although there has been minimal research on the effectiveness of brief public health interventions carried out in general dental practice, those carried out in other primary healthcare settings have demonstrated significant effects. ${ }^{17}$

This study indicates that significant numbers of patients attending the IDU have lifestyle habits that make them vulnerable to oral cancer. Dental access centres appear well placed to play a role in the primary prevention of oral cancer. An opportunity exists for access centres to provide opportunistic information about the risks of smoking and excess alcohol consumption to patients whose lifestyle habits place them at risk of developing oral cancer. However, it should be remembered that these patients are invariably in considerable pain when they attend, and may be disinterested in less immediate health issues. Effectiveness will also depend on overcoming reported barriers to preventive health services in dentistry, such as cost, time, lack of adequate incentives (eg Government targets or financial initiatives) and lack of routine enquiry into the smoking and drinking habits of patients. It has been reported that GDPs rarely ask about alcohol use and many feel uncomfortable doing so. ${ }^{18}$ However, a recent survey of dental patients indicated that they were supportive of dentists providing them with advice regarding alcohol use $^{19}$ and as such, dental practices should be encouraged to do so.

\section{SUMMARY}

The Government is committed to reducing the overall numbers of smokers. ${ }^{20}$ This study indicates that dental access centres are able to identify target groups as part of their routine triaging processes. If effective information programmes could be designed, it would be possible to use dental access centres as an effective way to selectively target risk group individuals. Commissioning bodies should consider investing in the provision of such healthcare messages in dental access centres.

1. Scully C, Felix D H. Oral medicine - update for the dental practitioner. Oral cancer. Br Dent J 2006; 200: 13-17

2. Conway D I, Stockton D L, Warnalulasuriya K A Ogden G, Macpherson L M. Incidence of oral and oropharygeal cancer in United Kingdom (19901999) - recent trends and regional variation. Oral Oncol 2006; 42: 586-592.

3. Spiro R H. Squamous cancer of the tongue. $C A$ Cancer J Clin 1985; 35: 252-256.

4. Llewellyn C D, Johnson N W, Warnakulasuriya K A $S$. Risk factors for oral cancer in newly diagnosed patients aged 45 years and younger: a case control study in Southern England. J Oral Pathol Med
2004; 33: 525-532.

5. Llewellyn C D, Linklater K, Bell J, Johnson N W, Warnakulasuriya K A S. An analysis of risk factors for oral cancer in young people: a case control study. Oral Oncol 2004; 40: 304-301.

6. West R, Alkhatib M N, McNeill A, Bedi R. Awareness of mouth cancer in Great Britain. Br Dent J 2006; 200: 167-169.

7. Office for National Statistics. General household survey 2005. London: Office for National Statistics, 2005.

8. West R, Witold Z, Przewozniak K, Jarvis M J. Can we trust national smoking prevalence figures? Discrepancies between biochemically assessed and self-reported smoking rates in three countries. Cancer Epidemiol Biomarkers Prev 2007; 16: 820-822.

9. Stockwell T, Donath S, Cooper-Stanbury M, Chikritzhs T, Catalano P, Mateo C. Under-reporting of alcohol consumption in household surveys: a comparison of quantity-frequency, graduated-frequency and recent recall. Addiction 2004; 99: 1024-1033.

10. Binnie W H, Cawson R A, Hill G B, Soaper A E. Oral cancer in England and Wales. A National study of morbidity, curability and related factors. London: HMSO, 1972. Studies on Medical Population Subjects No. 23.

11. Netuveli G, Sheiham A, Watt R. Does the 'inverse screening law' apply to oral cancer screening and regular dental check ups? J Med Screen 2006; 13: 47-50.

12. Mohad Yusof Z Y, Netuveli G, Ramli A S, Sheiham A. Is opportunistic oral cancer screening by dentists feasible? An analysis of the pattern of dental attendances of a nationally representative sample over 10 years. Oral Health Prev Dent 2006; 4: 165-171.

13. Speight P M, Palmer S, Moles D R et al. The cost-effectiveness of screening for oral cancer in primary care. Health Technol Assess 2006; 10(14): 1-144.

14. Humphris $\mathrm{G}$ M, Freeman $\mathrm{R}$, Clarke H M M. Risk perception of oral cancer in smokers attending primary care: a randomised controlled trial. Oral Oncol 2004; 40: 916-924.

15. Humphris G M, Field E A. An oral cancer information leaflet for smokers in primary care: results from two randomised controlled trials. Community Dent Oral Epidemio/ 2004; 32: 143-149.

16. Humphris $G M$, Field $E A$. The immediate effect on knowledge, attitudes and intentions in primary care attenders of a patient information leaflet: a randomized control trial replication and extension. BrDent J 2003; 194: 683-688.

17. Dyer T A, Robinson P G. General health promotion in general dental practice - the involvement of the dental team. Part 1: a review of the evidence of effectiveness of brief public health interventions. Br Dent J 2006; 200: 679-685.

18. Dyer T A, Robinson P G. General health promotion in general dental practice - the involvement of the dental team. Part 2: a qualitative and quantitative investigation of the views of practice principals in South Yorkshire. Br Dent J 2006; 201: 45-51.

19. Miller P M, Ravenel M C, Shealy A E, Thomas S. Alcohol screening in dental patients: the prevalence of hazardous drinking and patients' attitudes about screening and advice. J Am Dent Assoc 2006; 137: 1692-1698.

20. Department of Health. Choosing health: making healthy choices easier. London: Department of Health, 2004. Public Health White Paper Nov 2004. 